\title{
SERVIÇOS EDUCACIONAIS: DIRETRIZES, BASES DA EDUCAÇÃO E RESPONSABILIDADE CIVIL DOS CONTRATANTES
}

\author{
Helena Beatriz de Moura Belle ${ }^{1}$
}

\section{RESUMO}

Analisar a efetividade nos serviços educacionais diante das alterações na Lei de Diretrizes e Bases quanto à dinâmica dos cursos, recursos, titulação de professores e obrigatoriedade de divulgação dos planos de ação. O método dialético, metodologia qualitativa e técnicas de estudos em doutrinas e fontes primárias do direito nortearam a pesquisa. $\mathrm{O}$ cumprimento das exigências e o diálogo sobre o nível de satisfação de usuários deve ser prática de toda Instituição de Ensino Superior que planeja atuar de forma longeva. O contrário, além de implicações em autorização e funcionamento, de instituições e cursos, poderia ensejar ações envolvendo contratos educacionais.

Palavras-chave: Ensino superior. Exigências. Recursos. Efetividade.

\section{EDUCATIONAL SERVICES: GUIDELINES, BASIS OF EDUCATION AND CIVIL RESPONSIBILITY OF CONTRACTORS}

\begin{abstract}
Analyze the effectiveness of educational services in the face of changes in the Law of Guidelines and Bases regarding the dynamics of courses, resources, teacher qualifications and mandatory disclosure of action plans. The dialectical method, qualitative methodology and study techniques in doctrines and primary sources of law guided the research. Compliance with requirements and dialogue on the level of user satisfaction must be the practice of any Higher Education Institution that plans to act for a long time. The opposite, in addition to implications for authorization and operation, of institutions and courses, could lead to actions involving educational contracts.
\end{abstract}

Keywords: University education. Requirements. Resources. Effectiveness.

\section{INTRODUÇÃO}

\footnotetext{
${ }^{1}$ Doutora em Educação pela Pontifícia Universidade Católica de Goiás (PUC Goiás), Post Doctorado em Ciencias Jurídicas Y Garantías Constitucionales pela Universidad Nacional de La Matanza; Mestre em Engenharia de Produção com ênfase em Gestão de Negócios pela Universidade Federal de Santa Catarina; Especialista em Análise e Auditoria Contábil pela PUC Goiás, em Direito Empresarial e Advocacia Empresarial pela Universidade Anhanguera, em Direito Educacional pelo Centro Universitário Claretiano; Graduada em Direito e Ciências Contábeis pela PUC Goiás; coordena grupo de pesquisa na Escola de Direito e Relações Internacionais na PUC Goiás, Grupo de Estudos em Direito Empresarial (GEDE), linhas de pesquisas: Empresa e atuação empresarial e Institutos de Recuperação e de Falência.
} 
A Constituição da República do Brasil, de 5 de outubro de 1988, artigo 205, assevera que "a educação, direito de todos e dever do Estado e da família, será promovida e incentivada com a colaboração da sociedade, visando ao pleno desenvolvimento da pessoa, seu preparo para o exercício da cidadania e sua qualificação para o trabalho.” Também, aponta os agentes públicos e privados, responsáveis por ofertar o ensino, norteados por princípios que privilegiem a boa formação do cidadão.

A Lei $n^{\circ}$ 9.394, de 20 de dezembro de 1996 - Lei de Diretrizes e Bases da Educação, com fundamentos nos ditames da CF/1988, dispõe, em seu artigo $3^{\circ}$, um conjunto de 12 incisos definindo os princípios que deverão direcionar as atividades educacionais, nos cursos oferecidos em todos os níveis de ensino.

Os preceitos descritos, se materializados em conformidade com as orientações, possibilitariam resultados suficientes para viabilizar o ensino e instigar potencialidades dos estudantes quanto ao desempenho de suas competências, considerando o mundo do trabalho globalizado, competitivo e dinâmico. O distanciamento entre o discurso e a prática é visível, a efetividade entre as declarações dos direitos e garantias fundamentais, em sua maioria, ainda é precária.

Para além do ensino de qualidade desejada, ressalta-se, é imprescindível o empenho individual e coletivo, pois não bastam estruturas físicas, quadro ideal de professores e pessoal técnico-administrativo compatível, se os protagonistas - os estudantes - não se empenharem.

Assim, os dispositos expressos na Lei $\mathrm{n}^{\circ}$ 8.078, de 11 de setembro de 1990 (CDC), além da Lei no 9.394/1996, devem orientar a formação de profissionais da educação. Não apenas as estruturas tangíveis, porquanto, é fundamental o conhecimento para mediar o saber. No ensino superior os pilares ensino, pesquisa e extensão precisam ser indissociáveis e dependentes de formação em áreas específicas, multi, inter e transdisciplinares. O contrário seria inviabilizar o ensino e a inserção do profissional no mundo do trabalho.

De um lado, o direito à formação educacional adequada, de outro, a obrigação dos agentes de promover ensino de qualidade que motive o estudante, com ações guiadas por políticas públicas compatíveis, recursos suficientes e adequados, com o objetivo de satisfazer os usuários, indivíduos de diferentes ideologias e categorias sociais.

Tem-se, dessa forma, um ponto de partida para enfatizar algumas questões frágeis verificadas no percurso educacional, que geram inquietudes na sociedade, principalmente em pais e estudantes que anseiam pelo sucesso intelectual e profissional. Caso a instituição de 
ensino não possua recursos fundamentais e o estudante não alcance resultados satisfatórios, ou não se qualifique para o mercado de trabalho, quais seriam as responsabilidades das organizações ofertantes dos serviços educacionais? Verifica-se uma questão conflituosa, objeto de estudo nesta produção.

O estudo teve como fundamentação teórica a proferida por Nunes Júnior (2018), que trata dos direitos e garantias fundamentais, com foco nas perspectivas objetiva e subjetiva das normas definidoras dos direitos sociais e fontes das políticas públicas. Daí o impacto na responsabilidade civil daqueles que oferecem serviços educacionais; por Gonçalves (2018) e Venosa (2018), que abordam a responsabilidade civil e o dever de indenizar os usuários de serviços por possíveis perdas nas relações contratuais; e, por Marques, Benjamin e Miragem (2010), com reflexões sobre os direitos e defesa do consumidor.

O trabalho foi norteado pelo método dialético por envolver interpretação de realidades particulares, orientam Lakatos e Marconi (2017, p. 45), por penetrar no mundo dos fenômenos, considerando a ação recíproca das contradições inerentes aos acontecimentos e das alterações no diálogo persuasivo que ocorre na sociedade. Adotou-se pesquisa qualitativa, com utilização de técnicas de estudos bibliográficos, assim, asseveram, pode-se discutir aspectos mais profundos e descrever a complexidade do comportamento humano (p. 78).

$\mathrm{Na}$ primeira parte tem-se os conteúdos sobre os direitos e garantias de acesso à educação no Brasil. Na segunda, uma incursão sobre a relação contratual entre instituições de ensino e usuários dos serviços. A terceira trata da responsabilidade civil nos fatos jurídicos inerentes aos contratos de serviços educacionais e à obrigação de indenizar por perdas verificadas nas relações contratuais, por fim, têm-se as considerações finais.

\section{DIREITOS E GARANTIAS DE ACESSO À EDUCAÇÃO NO BRASIL}

O direito à educação está amparado na $\mathrm{CF} / 1988$, artigo 6º ; a promoção e incentivo à educação, como dever do Estado e da família, efetivada de forma colaborativa pela sociedade, com princípios orientadores, estão descritos no artigo 206, e, notadamente, o inciso VII, determina ser imprescindível a garantia de padrão de qualidade.

No Brasil, a eficácia dos direitos sociais, especificamente na área educacional, é fragilizada, pois, sua efetividade está intimamente relacionada à condição econômico-financeira do indivíduo. Verificam-se, a cada dia, pioras na desigualdade social, impactando nas oportunidades de ensino e as expectativas não são alentadoras.

Revista de Pesquisa e Educação Jurídica | e-ISSN: 2525-9636 | Encontro Virtual | v. 6 | n. 2 | 
Nunes Júnior (2018, p. 1.101) é incisivo ao abordar os princípios que definem os direitos sociais, afirmando tratar-se de normas de alto grau de abstração, tais como: direito à moradia, à segurança, à educação, dentre outros. Afirma que "malgrado a eficácia jurídica seja limitada, em razão do menor poder de produzir efeitos concretos imediatos na sua plenitude, tais normas devem ser estudadas em duas perspectivas", uma objetiva, outra subjetiva.

Na perspectiva objetiva, explica Nunes Júnior (2018, p. 1.102) "as normas definidoras dos direitos são mandamentos perenes para o Estado no sentido de que este tem a obrigação permanente de concretização e realização dos direitos fundamentais." Nesse aspecto, vinculam-se ações ostensivas de todos os órgãos do Estado, formalizadas em âmbito dos Poderes Executivo, Legislativo e Judiciário. Na segunda, subjetiva, declara (p. 1.103) que “entender que as normas definidoras dos direitos sociais não são capazes de produzir quaisquer efeitos jurídicos subjetivos significa negar a própria força normativa da Constituição."

Como se verifica, há firme e robusto compromisso de que a oferta de serviços educacionais possa atender a comunidade, todavia, são discursos e declarações de difícil alcance; falácias que se arrastam por séculos no Brasil. Em consequência, a sociedade é aviltada, ao considerar que não há plenitude no atendimento de seus direitos e garantias constitucionais fundamentais, em especial a educação.

Nas perspectivas de Nunes Júnior (2018) é indispensável a atuação do poder público, no sentido de cumprir suas políticas e metas, assim como de verificar se as organizações públicas e privadas de diferentes espécies, constituídas para fins de prestação de serviços no campo educacional, também cumprem suas obrigações. A inércia do poder público seria a negativação da tutela jurisdicional.

\section{RELAÇÃO CONTRATUAL ENTRE INSTITUIÇÕES DE ENSINO E USUÁRIOS}

A Lei $n^{\circ}$ 10.406, de 10 de janeiro de 2002, em seu artigo 421, dispõe que "a liberdade contratual será exercida nos limites da função social do contrato", com observância na Declaração de Direitos de Liberdade Econômica.

Gonçalves (2018, p. 24) explica que "a concepção social do contrato apresenta-se, modernamente, como um dos pilares da teoria contratual. Por identidade dialética guarda intimidade com o princípio da 'função social da propriedade'", consoante a CF/1988, artigo $5^{\circ}$, 
inciso XXIII e artigo 170, caput e inciso III. O autor é pragmático ao afirmar que "a função social do contrato institui, assim, princípio moderno a ser observado pelo intérprete na aplicação dos contratos. Alia-se aos princípios tradicionais, como os da autonomia da vontade e da obrigatoriedade, muitas vezes impedindo que estes prevalecem."

$\mathrm{Na}$ área do ensino existem os contratos de serviços educacionais, orientados pela Lei $n^{\circ}$ 10.406/2002, artigo 593, que trata da "prestação de serviços que não estiver sujeita às leis trabalhistas ou a lei especial [...]". No referido dispositivo, o artigo 594 dispõe que "toda espécie de serviço ou trabalho lícito, material ou imaterial, pode ser contratada mediante retribuição", que consiste na contraprestação aos serviços cobrados em pecúnia pelo prestador aos usuários. Ao mínimo, deve-se exigir habilitação e competências que permitam a ambas as partes lograrem êxito.

O artigo 606, da mesma lei, orienta que, "se o serviço for prestado por quem não possua título de habilitação, ou não satisfaça requisitos outros estabelecidos em lei, não poderá quem os prestou cobrar a retribuição normalmente correspondente ao trabalho executado.” Assim, não basta a formação superior de graduação ou de tecnólogo, visto que são muitos os dispositivos legais que determinam estudos mais avançados. No caso, são requeridos dos profissionais as especializações, lato sensu, e cursos em programas stricto sensu, mestrado e doutorado, além de preparo em áreas afins, para desenvolver bem o trabalho educacional.

O que se verifica é uma gama de dispositivos que formalizam práticas e orientam os usuários de serviços de qualquer natureza. Entretanto, não são raras as ocasiões nas quais os usuários de serviços públicos e privados têm seus direitos aviltados sem que nada aconteça, ou seja, os direitos e garantias declarados na $\mathrm{CF} / 1988$ de nada adiantam para uma boa parte da população, considerada hipossuficiente, isto é, com poucos ou insuficientes recursos financeiros para o financiamento de suas necessidades básicas.

As práticas lesivas são tratadas na Lei n 10.406/2002, artigo 445, identificadas como vícios e, em várias circunstâncias, denominados vícios redibitórios. Ressalta-se, porém, somente são envolvidos bens de natureza móvel e imóvel, quando há defeitos ocultos que tornem o negócio contratado impróprio ao uso; o que permite direito de obter redibição ou abatimento no preço, em determinados prazos, a depender do objeto negociado. Todavia, dispõe o $\S 1^{\circ}$ que, "quando o vício, por sua natureza, só puder ser conhecido mais tarde, o prazo contar-se-á do momento em que dele tiver ciência" da perda. 
Por analogia, imagina-se, seria possível invocar os direitos inerentes aos serviços educacionais, cujos usuários conseguiriam, quando necessário, tê-los protegidos em determinadas situações, como, por exemplo, por não terem clareza da importância dos serviços, o que poderia ser tratado como direitos difusos devido a especificidade dos serviços disponibilizados.

A respeito do assunto, Venosa (2018, p. 24) orienta que "o princípio da socialidade" adotado na Lei no 10.406/2002, "reflete a prevalência dos valores coletivos sobre os individuais, sem perda, porém, do valor fundamental da pessoa humana." Assim, o sentido que se apregoa é o de que o ordenamento civil vigente tem convergências com a realidade brasileira contemporânea, e mitigar a aplicabilidade da lei aos casos concretos, que possam impactar nos resultados da efetividades dos direitos fundamentais da pessoa, poderia amenizar os problemas decorrentes da atuação de diversas organizações, públicas e privadas.

\section{SERVIÇOS EDUCACIONAIS: ALTERAÇÕES NA LEI DE DIRETRIZES E BASES E RESPONSABILIDADE CIVIL NOS CONTRATOS}

Os serviços educacionais estão incluídos no conjunto de atividades que podem ser praticadas, considerando o princípio da livre iniciativa, disposto na CF/1988, artigo 170, caput, assim, argumenta Ramos (2017, p. 587), “os empresários devem ter total liberdade para realizar negócios - desde que lícitos, obviamente -, bem como assumir os riscos de contratações malfeitas." O parágrafo único do citado artigo, no entanto, determina que "é assegurado a todos o livre exercício de qualquer atividade econômica, independentemente de autorização de órgãos públicos, salvo nos casos previstos em lei."

Além das normas constitucionais, a LDB/1996, artigo $7^{\circ}$, estabelece que "o ensino é livre à iniciativa privada". Entretanto, devem ser atendidas algumas condições, quais sejam: "I - cumprimento das normas gerais da educação nacional e do respectivo sistema de ensino; II autorização de funcionamento e avaliação de qualidade pelo poder público; III - capacidade de auto financiamento", com ressalvas à destinação de recursos, que podem alcançar o setor privado, conforme $\mathrm{CF} / 1988$, artigo 213.

A respeito das condições e liberdade para atuação dos interessados, é dever do Estado verificar se de fato as ações estão de acordo com os ditames legais; caso contrário, deverá inibir atos jurídicos que não coadunem com os princípios definidos na CF/1988. 
Marques, Benjamin e Miragem (2010, p. 37) são contundentes ao argumentarem que “é mister hoje destacar a importância da análise do campo de aplicação subjetivo de uma lei especial.” Os autores orientam que "a concentração no sujeito de direitos é hoje característica de nosso direito privado: é para proteger este sujeito que leis especiais são criadas, microssistemas como o CDC, que ajudam a formar o complexo novo sistema do direito privado atual."

Em que pese a liberdade para exercer negócio econômico, o empresário, a empresa, as sociedades empresárias ou não empresárias, dispõe a CF/1988, devem se ater aos preceitos que guiam a atividade econômica. No caso de serviços educacionais é imprescindível que se observe a função social da propriedade e dos contratos, os direitos de liberdade econômica, a livre concorrência, o respeito ao consumidor, a defesa do meio ambiente, a busca do pleno emprego e a redução das desigualdades regionais e sociais, para tornar real um ensino de qualidade que viabilize a atuação profissional com sucesso.

\subsection{ATUAÇÃO E RESPONSABILIDADE CIVIL DE INSTITUIÇÕES DE ENSINO SUPERIOR}

A educação superior é destacada na Lei no 9.394/1996, artigos 43 a 57, sendo suas finalidades ressaltadas no artigo 43, dentre muitos fins, têm-se o estímulo a formação com espírito crítico e diversidade quanto a atuação em áreas, incentivo ao trabalho e pesquisa, propagação do saber, aperfeiçoamento cultural e profissional, conhecimento dos problemas mundiais, promoção de atividades de extensão, atuação em favor da universalização e do aprimoramento da educação.

Como se verifica, alcançar tais finalidades, ampliadas e muito importantes para a sociedade e para o indivíduo em sua formação superior, não é tarefa fácil para as IES, sobretudo quanto a disponibilizar corpo docente com formação e titulação adequadas, experiência de sala de aula, conhecimento da ambiência local, vontade e habilidades para estimular e promover o conhecimento.

Lembra-se, o sucesso no ensino superior, é cediço, está diretamente relacionado aos resultados satisfatórios na educação básica e esta indissociabilidade, em geral, nem sempre é de percepção dos usuários de serviços educacionais em nível superior.

No que concerne aos cursos e programas, a LDB/1996, artigo 44, determina que a educação superior contemple cursos nas modalidades sequenciais e de graduação, abertos a 
candidatos que tenham concluído o ensino médio, com observância das peculiaridades de cada um; de pós-graduação, envolvendo programas de mestrado e doutorado, cursos de especialização e aperfeiçoamento, abertos a candidatos diplomados em cursos de graduação e que atendam às exigências das instituições de ensino ofertantes.

A LDB/1996, artigo 45, expressa que neste nível de educação será ministrada em instituições de ensino superior, públicas ou privadas, porém, o artigo 46, orienta que "a autorização e o reconhecimento de cursos, bem como o credenciamento de instituições de educação superior, terão prazos limitados, sendo renovados, periodicamente, após processo regular de avaliação."

As exigências para a oferta do ensino, na renovação do reconhecimento, são complexas e requerem atendimento, pela IES, de diversas adequações, conforme LDB/1996, artigo $46, \S 1^{\circ}$, ao dispor que, se forem identificadas deficiências na avaliação, será concedido prazo para saneamento e "haverá reavaliação, que poderá resultar, conforme o caso, em desativação de cursos e habilitações, em intervenção na instituição, em suspensão temporária de prerrogativas da autonomia, ou em descredenciamento". Algumas IES devem se adequar com base em termos de ajustamentos emitidos pelos órgãos competentes.

No caso do desenvolvimento do ensino superior, nota-se, as instituições, independentemente da natureza jurídica, devem cumprir com seu objeto e função social, para que possam oferecer e manter os serviços. Recentemente, a obrigação de divulgar os serviços e atividades acadêmico-administrativas de todos os cursos programados e desenvolvidos, foi intensificada, conforme ordenamento ordinário e especial vigente no Brasil.

Essas exigências do poder público impactam nas ações das IES, notadamente, nos contratos de serviços educacionais e, neste campo, ocorreram inúmeras alterações e inclusões substanciais do e no referido artigo 47 da LDB/1996, com a promulgação da Lei $\mathrm{n}^{\circ} 13.168$, de 6 de outubro de 2015; no que concerne ao $\S 1^{\circ}$, incluiu-se o seguinte texto complementar para exigir publicação de propostas bem antes do início do semestre letivo, mas, para algumas IES, não há certeza se haverá estudantes para formar turma nos semestres presente e vindouros.

Com as alterações e aditamentos, indubitavelmente, verifica-se que a proposta pedagógica, a dinâmica do curso, as disciplinas e demais atividades, a formação dos membros do corpo docente responsável pela implementação do ensino, devem ser publicadas para permitir acesso aos seus usuários, estudantes, razão de ser da IES, que contrata os serviços educacionais, assim como outros interessados, financiadores, avaliadores, comunidade em 
geral. Todas essas adaptações nos cursos e das IES devem ser levadas ao conhecimento dos usuários com muita antecedência, restando saber, contudo, se estas orientações normativas serão cumpridas a contento.

O descumprimento de determinações legais impactará em altos riscos aos resultados pretendidos e, seguramente, influenciará nas decisões sobre a manutenção das atividades educacionais, na renovação de autorização para atuação e renovação de reconhecimento do curso, consequentemente, nos contratos e na responsabilidade civil da IES que não oferecer, conforme prometido, serviços de qualidade que favoreçam os anseios sociais.

A respeito dessas exigências legais e seu não cumprimento pela IES, considerando tratar-se de direito coletivo, Marques, Benjamin e Miragem (2010, p. 37), argumentam que "o aplicador da lei deve examinar o conflito com olhos plurais, pois, a nova teoria do sujeito é outra: o sujeito está fragmentando e é plural, como é o grupo de consumidores.”

Caso, pois, um usuário do sistema educacional, cujos serviços sejam oferecidos por uma IES, venha a reclamar da qualidade de um curso, alegando descumprimento de procedimentos mínimos descritos na LDB/1996, artigo 47, ou não cumprimento de qualquer outro dispositivo obrigatório, sendo a qualidade dos serviços questionada, individualmente e também em relação aos demais usuários, o direito deverá ser estendido a todo o grupo atingido.

\subsection{REPARAÇÃO DO DANO NO ORDENAMENTO BRASILEIRO E IMPACTOS EM INSTITUIÇÕES DE ENSINO SUPERIOR}

A Lei $n^{\circ}$ 10.406/2002 dispõe, em seu artigo 927, que "aquele que, por ato ilícito (arts. 186 e 187) causar dano a outrem, fica obrigado a repará-lo.” O parágrafo único do referido artigo é taxativo ao dispor que "haverá obrigação de reparar o dano, independentemente de culpa, nos casos especificados em lei, ou quando normalmente desenvolvida pelo autor do dano implicar, por sua natureza, risco para os direitos de outrem.”

A respeito dos atos ilícitos, a mesma lei determina que "aquele que, por ação ou omissão voluntária, negligência ou imprudência, violar direito e causar dano a outrem, ainda que exclusivamente moral, comete ato ilícito" (art. 186). E mais: estabelece o artigo 187 que "também comete ato ilícito o titular de um direito que, ao exercê-lo, excede manifestamente os limites impostos pelo seu fim econômico ou social, pela boa-fé ou pelos bons costumes." 
A assertiva remete, fundamentalmente, à interpretação do artigo 606, da citada lei, pois, no caso em que o serviço for executado "por quem não possua habilitação, com a devida comprovação mediante diploma ou certificação, ou não satisfaça requisitos outros estabelecidos em lei, não poderá quem os prestou cobrar a retribuição normalmente correspondente ao trabalho executado."

Assim, com os dispositivos da lei civil, do CDC, da legislação que orienta a renovação de reconhecimento de IES, e as alterações relativas a LDB/1996, acerca dos serviços educacionais, é preciso observar paradigmas apropriados para o desenvolvimento do ensino, pois, ao contrário, poderá haver penalidades pecuniárias, por indenização.

As IES que não conseguirem cumprir suas obrigações contratuais correrão o risco de ter o credenciamento suspenso ou interrompido e perder a autorização para oferta de cursos. Todavia, seria uma decisão drástica, ao considerar a situação dos estudantes, em que pese a perspectiva objetiva discutida por Nunes Júnior (2018). A obrigatoriedade do agir de todos os Poderes, na eficácia dos direitos fundamentais, afirma o autor (p. 1.102): "como corolário da dimensão objetiva dos direitos fundamentais sociais, a função por eles determinada, incumbindo ao Estado o dever de proteção de seu exercício, não somente em relação às ingerências dos poderes públicos, como também às ingerências dos próprios particulares" e de quaisquer outros envolvidos que causem danos a outra parte.

Nunes Júnior (2018, p. 1.103) explica que em perspectiva subjetiva da norma definidora dos direitos sociais e fontes das políticas públicas, "ainda que alto o grau de abstração, ou considerado o caráter pragmático da norma constitucional, a força normativa da Constituição lhe autoriza a gerar situações subjetivas.” Isto implica que, independentemente das espécies organizacionais, também da ocorrência de determinados fatos jurídicos, sempre que demandado, o dever do Estado de encontrar solução para minimizar os conflitos e, se for o caso, determinar reparações de danos causados a outrem, especialmente, quando os usuários dos serviços são consumidores finais.

Em geral, argumenta Gonçalves (2018, p. 362), na prestação de serviços, têm-se o "contrato bilateral ou sinalagmático, porque gera obrigações para ambos os contratantes. $\mathrm{O}$ prestador assume uma obrigação de fazer perante o dono do serviço, que, por sua vez, compromete-se a remunerá-lo pela atividade desenvolvida." Nesse sentido, continua o autor, na lei civil, a prestação de serviços, “embora não adstrita a esse limite, sendo regida pelo 
princípio da autonomia da vontade, não pode afastar-se, todavia, das cláusulas gerais que consagram a função social do contrato e o princípio da boa-fé objetiva (CC, arts. 421 e 422)."

Deve-se, desse modo, observar as convergências no campo de aplicação material entre o CDC/1990 e CC/2002, na interpretação de Marques, Benjamin e Miragem (2010, p. 37), que argumentam: "se a lei é feita para protegê-los, seu campo de aplicação subjetivo não pode ser mais somente 'individual', e sim, necessariamente, também coletivo ou plural." Os autores afirmam que o CDC deve ser aplicado em favor de um conjunto de usuário, portanto, todos aqueles que tenham legitimidade devem agir com eficácia em relação ao referido direito. Nessa acepção, as IES correriam sérios riscos, com tendências a insolvência irrecuperável, a depender do número de cursos oferecidos, do número de estudantes e de egressos, de diversas turmas.

Para Venosa (2018, p. 18), a compreensão sobre a responsabilidade "implica sempre exame de conduta voluntária de um dever jurídico. Sob tal premissa, a responsabilidade pode ser de várias naturezas, embora ontologicamente o conceito seja o mesmo." O autor aborda a responsabilidade civil e penal e, conquanto não seja o foco do presente estudo, é importante ressaltar, ao considerar a conduta violadora dos direitos e garantias, há que admitir o envolvimento de questões do campo civil, administrativo e penal. O autor é incisivo ao afirmar sobre a aplicabilidade da decisão nos dois campos, penal e cível (p. 19): “a sentença penal condenatória faz coisa julgada no cível quanto ao dever de indenizar o dano decorrente da conduta criminal, na forma do art. 91, I, do Código Penal, 63 do Código de Processo Penal (CPP) e 584, II, do Código de Processo Civil (CPC)."

As incursões de Venosa (2018) são convergentes com as de Marques, Benjamin e Miragem (2010), pois, deve-se adotar todos os institutos em favor dos direitos e garantias dos consumidores, e também necessário se considerar que, se houver descumprimento ao que dispõem os institutos da responsabilidade civil, concernente aos atos praticados em desacordo com os preceitos admissíveis, assim como o não atendimento dos critérios e atuação das IES, a publicização de procedimentos que envolvam a dinâmica dos cursos, transgredindo, então, um dever jurídico, em desacordo com a LDB/1996, seguramente o consumidor poderá alegar ilícito civil, administrativo e penal.

Questiona-se, com isto, sobre o que poderia ocorrer se determinada instituição de ensino oferecesse, em publicidade de qualquer natureza, curso superior com declarações de excelência e garantia de desempenho com sucesso no mercado de trabalho, e depois da 
conclusão desse curso, todavia, o graduado não estivesse habilitado adequadamente, conforme a oferta inicial, e não fosse aprovado em concurso público na área ou em qualquer outro certame, perdendo oportunidades de emprego ou de seguir a carreira, como, por exemplo, cargos públicos e privados, exercício de atividade profissional, Exame da Ordem, magistratura, promotoria, processos seletivos para ingressos em formação mais elevada.

Em caso como esse, indaga-se sobre a responsabilidade da instituição de ensino perante o aluno, diante da oferta publicitária e da celebração do contrato de prestação de serviços educacionais que não tenha logrado êxito. Necessário se faz a verificação das medidas judiciais cabíveis e, ainda, o ônus da prova, mas, o Estado tem o dever de averiguar e tomar as medidas pertinentes para garantir os direitos previstos no ordenamento legal.

\subsection{RESPONSABILIZAÇÃO E PENALIDADES NA ATUAÇÃO DE INSTITUIÇÕES DE ENSINO SUPERIOR}

As instituições ofertantes de cursos superiores, define a LDB/1996, devem avançar em suas ações, e suas características devem harmonizar os pilares ensino, pesquisa e extensão:

\footnotetext{
Art. 52. As universidades são instituições pluridisciplinares de formação dos quadros profissionais de nível superior, de pesquisa, de extensão e de domínio e cultivo do saber humano, que se caracterizam por:

I - produção intelectual institucionalizada mediante o estudo sistemático dos temas e problemas mais relevantes, tanto do ponto de vista científico e cultural, quanto regional e nacional;

II - um terço do corpo docente, pelo menos, com titulação acadêmica de mestrado ou doutorado;

III - um terço do corpo docente em regime de tempo integral.

Parágrafo único. É facultada a criação de universidades especializadas por campo do saber.
}

Como se verifica, trata-se de complexa instituição, para atuação em diversificadas áreas do conhecimento, e é preciso estar preparada para envolver os três pilares. A responsabilidade é enorme. Destaca-se, no dispositivo citado, o quantitativo de professores com titulação em cursos stricto sensu e verifica-se um triplo conflito, pois, a LDB e o MEC mediante Instrumento de Avaliação, não dispõem sobre elementos quantitativos, e sim, qualitativos. Todavia, algumas notas técnicas mencionam o número ideal e a avaliação em conformidade com indicadores de qualificação dos membros do corpo docente.

Ressalta-se que faculdades, centros universitários e outras modalidades de instituições de ensino superior também devem ter iguais preocupações em relação aos 
serviços realizados, visto que as exigências do poder público são as definidas em geral, aplicáveis a todas as IES e, no que se refere aos contratos educacionais, não há que afastar tais organizações com número menor de ações implementadas, portanto, com quantitativo menor de cursos oferecidos, consequentemente, com número reduzido de clientes/consumidores/estudantes.

A Lei $n^{\circ} 8.078 / 1990$ dispõe sobre a proteção do consumidor e apregoa, em seu artigo $2^{\circ}$, que "consumidor é toda pessoa física ou jurídica que adquire ou utiliza produto ou serviço como destinatário final." Compreende-se, pois, que estão aí incluídos os serviços educacionais.

O ordenamento citado propaga, em seu artigo $3^{\circ}$, a definição de fornecedor, determinando tratar-se de qualquer pessoa física ou jurídica, de natureza pública ou privada, de origem nacional ou estrangeira, além dos entes despersonalizados, "que desenvolvem atividade de produção, montagem, criação, construção, transformação, importação, exportação, distribuição ou comercialização de produtos ou prestação de serviços.”

Verifica-se, portanto, que a prestação de serviços está no rol dessas atividades, o que se confirma pelos ditames do $\S 2^{\circ}$ do aludido artigo, ao orientar que "serviço é qualquer atividade fornecida no mercado de consumo, mediante remuneração, inclusive as de natureza bancária, financeira, de crédito e securitária, salvo as decorrentes das relações de caráter trabalhista."

O que se poderia considerar caso o ensino não propiciasse o resultado desejado? Não se pode olvidar que a prática do ensino vem, há anos, sendo fator de preocupação de todos os envolvidos. Professores, pesquisadores, diretores, comunidade, pais, estudantes, têm manifestado sobre a precariedade quanto aos recursos humanos, econômicos e financeiros, as diretrizes curriculares nacionais, estaduais e municipais e, especialmente, os conteúdos de suas matrizes curriculares.

Insta salientar, ainda, a situação dos estudantes, que, em determinadas circunstâncias, apresentam sérias limitações que impedem seu comparecimento à escola. São questões de natureza cognitiva ou socioeconômica (alimentação inadequada; falta de tratamento médico; experiências de sérios problemas familiares; utilização de drogas lícitas e ilícitas), impedindoos, pois, de usufruir plenamente dos conteúdos propostos pela IES. Ressalta-se, a percepção do aprendizado pelo estudante e a falta de clareza sobre os objetivos e mecanismos propostos, pela complexidade dos procedimentos educacionais que envolvem o ensino superior. 
A responsabilidade civil nas relações de consumo, esclarece Gonçalves (2018, p. 65), conforme determinado na CF/1988, artigo $5^{\circ}$, Inciso XXXII, fortaleceu-se com a promulgação da Lei $n^{\circ} 8.078 / 1990$ - CDC -, de ordem pública e de interesse social, ao considerar a premissa de que o consumidor é a parte vulnerável das relações de consumo, sendo, então, necessário buscar meios de equilibrar as relações entre os protagonistas. Expressa o autor, (p. 66) e "tal diploma legal é abrangente, tendo repercutido profundamente nas diversas áreas do direito, inovando em aspectos de direito penal, administrativo, comercial, civil e processual civil", com a inclusão do ordenamento empresarial e societário, no CC/2002. Este avanço se deu em decorrência do consumo em massa e, ainda, devido à atuação dos conglomerados econômicos. Assim, "os princípios tradicionais da nossa legislação privada já não mais bastavam para reger as relações humanas, sob determinados aspectos”, (p. 66), explica o autor.

Gonçalves (2018, p. 66) elucida que, no CDC/1990, "tanto a responsabilidade pelo fato do produto ou serviço como a oriunda do vício do produto ou serviço são de natureza objetiva, prescindindo do elemento culpa a obrigação de indenizar atribuída ao fornecedor." Continua: "estipula-se a reparação de danos, tanto patrimoniais como morais, na tutela da própria $\mathrm{CF} / 1988$ (art. 5, V) e sem prejuízo de sancionamentos outros cabíveis.”

Nesse campo jurídico, argumenta o mesmo autor (2018, p. 66), prevalece a obrigação de ressarcir nos casos de vício, falta ou insuficiência de informações, sejam os danos causados às pessoas ou aos bens, e nestes, seja em razão de problemas intrínscos e extrínsecos ou de serviço contratados. Então, "são limitadas as excludentes invocáveis pelo agente, 'só' não sendo responsabilizado o fornecedor quando provar a culpa exclusiva do consumidor ou de terceiro, que não colocou o produto no mercado ou que, embora haja colocado o produto no mercado, o defeito inexiste (CDC, art. 12).”

Compreende-se, nesse cenário, que a falta de capacidade do estudante, portanto, não poderá dar direito a ele de demandar e questionar sobre a qualidade do ensino, nos casos em que a IES se propõe e realiza um trabalho compatível com as orientações normativas vigentes. Importante lembrar, trata-se de competência, formação, e não, de habilidade. Esta se adquire com a práxis, com as experiências, que, no caso, relacionam-se ao conhecimento voltado para as relações sociais e as reflexões políticas, econômicas, sociais e morais, que poderão guiar o estudante, futuro profissional, na condução de sua carreira. Desse modo, é provável que o profissional tenha competência, porém, a habilidade esteja comprometida, salientando-se que 
os serviços educacionais são atribuições de meio e, nem sempre, alcança-se resultados exitosos.

A escola, consequentemente, não pode ficar refém dos desejos e senso comum de estudantes e de seus pais ou responsáveis; ao contrário, deve estar preparada para desenvolver o ensino de boa qualidade, norteada por instrumentos apropriados.

Os instrumentos citados, relacionados às atividades educacionais, devidamente publicados e materializados, poderão orientar adequadamente as ações de todos os atuantes na escola, para o fiel cumprimento de suas obrigações civis e acadêmicas. O não cumprimento das orientações acadêmico-administrativas ensejaria a aplicação de processo disciplinar, tanto nas falhas dos membros do corpo docente, quanto técnico-administrativo e corpo discente. A solução para os conflitos e ajustes de condutas devem ser tratados, preferencialmente, na forma administrativa, o que seria ideal, mas, não sendo possível, a celeuma seria discutida e resolvida em âmbito judicial, cabendo ao Estado o dever de solucionar os conflitos e fragilidades vivenciadas na IES.

$\mathrm{Na}$ esfera do Poder Judiciário tais enfrentamentos podem resultar em direitos e obrigações tanto da IES e de seus membros, quanto de estudante e seus familiares. Não são raros os casos em que os Tribunais de Justiça determinem indenizações a professores e a membros diretivos, por falhas cometidas por alunos. Aos estudantes também é permitido ter seus direitos e garantias preservados, em ações cíveis, em caso de descumprimento do contrato pelas instituições de ensino, inclusive o direito de avançar para o campo penal. Ainda, a IES, na condição de agente especializado poderá ser penalizada se acaso não cumprir com suas obrigações educacionais, em âmbito administrativo, civil ou penal.

Pode-se afirmar, assim, que, por ser a educação atividade relevante, fundamental em toda a existência do indivíduo, aquele que tem direito não pode estar refém de políticas e práticas precárias e ter os seus direitos envilecidos. A luta pela efetividade do direito, e a atuação dos órgãos públicos e entidades privadas responsáveis, deve ser uma constante.

As escolas, em geral, no desempenho de sua função social institucional, devem se preparar para desenvolver ensino de boa qualidade, com o intuito de promover o maior benefício possível à sociedade, em cumprimento aos princípios constitucionais, artigos $3^{\circ}$, 209 e 227. Dispõe a LDB/1996 que a educação deve preparar o estudante para que ele exerça seu trabalho e siga sua vida com dignidade independentemente de a instituição educacional 
ser de direito público ou privado. Por seu lado, o próprio estudante e seus familiares devem se comprometer para que o aprendizado possa propiciar êxito na atividade profissional e social.

A responsabilidade dos estabelecimentos de ensino com seus educandos configura relação de sonsumo, e, neste entendimento, aduz o artigo $14, \S 3^{\circ}$ do CDC, que "o fornecedor de serviços só não será responsabilizado quando provar: I - que tendo prestado o serviço, o defeito inexiste"; e, se houver, "II - a culpa exclusiva do consumidor ou de terceiros." Como se verifica, há complexas discussões nas interpretações dos autores analisados neste estudo.

Em que pesem todas as divergências no campo educacional pode-se argumentar que a medida judicial cabível, nos casos da relação de consumo, será uma ação de indenização por danos materiais e morais, com base na lei de defesa do consumidor, pois a Lei $\mathrm{n}^{\circ}$ 10.406/2002, artigo 593, rege de forma subsidiária a prestação de serviços, isto é, na falta de lei especial.

O CDC dispõe sobre a prestação de serviço sem vício, artigos 18 a 25, e, de tal modo, a responsabilidade civil da IES é regulada, principalmente, por esta lei, porque a atividade está enquadrada nas relações consumerista, vinculadas aos direitos coletivos.

Nessa acepção, Diniz (2017, p. 481) explica:

\begin{abstract}
A defesa coletiva será exercida quando se tratar de interesse ou direitos difusos, ou seja, os transindividuais, de natureza indivisível, de que sejam titulares pessoas indeterminadas e ligadas por circunstâncias de fato; interesses ou direitos coletivos, isto é os transindividuais de natureza indivisível de que seja titular grupo, categoria ou classe de pessoas ligadas entre si ou com a parte contrária por uma relação jurídica base; interesses ou direito individuais homogêneos, assim entendidos os decorrentes de origem comum (art. 811, parágrafo único, I a III).
\end{abstract}

O posicionamento da autora está fundamentado nos dispositivos legais vigentes e, seguramente, deve provocar preocupações aos que exercem atividades educacionais em nível superior. No que se refere ao ônus da prova, a responsabilidade objetiva está consagrada, como regra geral, pelo artigo 14 do CDC, por determinar que "o fornecedor de serviços responde, independentemente da existência de culpa, pela reparação dos danos causados aos consumidores por defeitos relativos à prestação dos serviços, bem como por informações insuficientes ou inadequadas sobre sua fruição e riscos."

A responsabilidade da instituição quanto à qualidade do serviço prestado está amparada no CDC, artigo 20. O estudante, entretanto, tem o direito e o dever de assistir ao número fixado de aulas conforme carga horária imposta por lei; as aulas devem ser ministradas com boa qualidade, em espaço físico que favoreça o aprendizado. Assim, caberá à 
instituição responsabilizar-se pelos recursos necessários ao fiel cumprimento do contrato, isto é: corpo docente com competências e habilidades compatíveis com o ensino proposto; corpo técnico-administrativo com preparo para o exercício de suas funções; além de móveis, utensílios e equipamentos, espaço apropriado para sala de aula, ou outros recursos requeridos, para que os serviços sejam prestados a contento.

Diante da responsabilidade revelada pelo acometimento de prejuízo de algo ou a alguém, tem-se que verificar e determinar o valor da indenização que, conforme a Lei $\mathrm{n}^{\circ}$ 10.406/2002, artigo 944, "mede-se pela extensão do dano.” O artigo 945 poderá favorecer a IES que estiver envolvida com o fato jurídico e com a participação de determinado estudante que venha a demandar em desfavor aos serviços prestados, pois consta que, "se a vítima tiver concorrido culposamente para o evento danoso, a sua indenização será fixada tendo-se em conta a gravidade de sua culpa em confronto com a do autor do dano."

A interpretação do artigo 950 do ordenamento citado é importante, posto que, ao observar que, em determinadas circunstâncias, a analogia deve ser aplicada ao fato verificado, pois:

Se da ofensa resultar defeito pelo qual o ofendido não possa exercer o seu ofício ou profissão, ou se lhe diminua a capacidade de trabalho, a indenização, além das despesas de tratamento e lucros cessantes até ao fim da convalescença, incluirá pensão correspondente à importância do trabalho para que se inabilitou, ou da depreciação que ele sofreu.

O parágrafo único do artigo em comento determina que o prejudicado poderá, se preferir, exigir que o valor da indenização seja estimado e o pagamento ocorra em uma única parcela. No caso dos serviços educacionais seria de difícil mensuração a perda resultante de um ensino realizado por IES que não tenha se preparado e disponibilizado os recursos necessários, mas, o Estado deverá apresentar solução ao caso, ainda que em valores estimados.

Neste estudo não se pretendeu discutir a impossibilidade de exercício profissional, por problemas de saúde, de deficiência física, mental ou psicológica da pessoa, de verificar sua habilitação para o exercício da profissão, conforme opção, ingresso e realização de cursos superiores, para, na sequência, atuar no mercado de trabalho, mediante também verificação das habilidades de cada profissional. Tão pouco analisar o desenvolvmento das atividades por meio de utilização de plataformas digitais, por aulas síncronas e assíncronas, em virtude da situação de pandemia do Coronavírus. A pretensão é investigar a discussão sobre novas 
situações que envolvem o mundo jurídico na relação contratual no campo da educação, assim como a responsabilidade civil e de indenização por danos causados, se e quando houver, aos usuários de serviços educacionais.

\section{CONSIDERAÇÕES FINAIS}

O estudo permitiu analisar o ordenamento legal vigente concernente ao dever de oferecer educação e atuação de organizações de ensino superior. Afirma-se que os princípios e garantias fundamentais declarados na $\mathrm{CF} / 1988$, perpassando por regulamentação ordinária e extravagante, além de outros atos orientadores específicos do Ministério da Educação, constitui um rol expressivo de orientações que podem favorecer o desenvolivimento ideal do ensino.

O Código Civil em vigor dispõe sobre a boa-fé objetiva e a função social dos contratos que devem guiar a celebração de acordos; também a responsabilidade civil, os danos e as formas para reparação quanto à materialização desses contratos. Dentre várias espécies, têm-se os contratos de prestação de serviços que, neste o estudo, teve foco nos acordos educacionais, celebrados com o intuito de dar segurança jurídica e acadêmica a todos os envolvidos.

Verificou-se que o serviço educacional tem como objeto um conteúdo imaterial, inalienável e que influenciará toda a vida do aluno. A instituição, por conseguinte, deverá promover a formação do estudante e, por sua vez, este precisará se dedicar para cumprir todos os projetos propostos, divulgados previamente e acompanhados, em processos midiáticos diversificados, por interessados diversos, inclusive por órgãos que tenham competência para credenciar e autorizar, renovar credenciamentos e autorização de cursos, bem como suspender ou penalizar aquelas instituições que não cumpram suas obrigações educacionais.

A LDB/1996, com suas exigências contidas no artigo 47, orienta sobre os requisitos norteadores da atividade educacional, conforme analisado; e o não atendimento a tais normas poderá suscitar demandas judiciais por parte dos usuários finais, com possíveis reclamações sobre as fragilidades e a não efetividade dos contratos, em que pese a responsabilidade do estudante quanto ao compromisso para que os resultados sejam satisfatórios e permitam o favorecimento da carreira profissional, independentemente da área escolhida. 
A IES, por conseguinte, deve planejar suas ações para que o ensino possa ser orientado por instrumentos que contemplem políticas e práticas educacionais compatíveis com os objetivos, além de atender os aspectos definidos em suas matrizes dispostas nas Diretrizes Curriculares Nacionais para os cursos propostos, em quaisquer níveis. Entretanto, não poderá ficar refém dos desejos e senso comum de estudantes descomprometidos com o saber.

Verificou-se que as limitações são visíveis, nem sempre as IES conseguem cumprir rigorosamente suas obrigações institucionais, razão pela qual o tema é ainda carente de pacificação. Os autores que fundamentaram este estudo, em suas várias abordagens, são convergentes em relação ao nível de responsabilidade de cada membro atuante nas instituições. No caso da responsabilidade civil fortes foram os argumentos sobre o princípio da boa-fé objetiva e a função social dos contratos.

No que se referem aos direitos fundamentais, coloca-se no centro da questão a obrigatoriedade de que todos os Poderes - Legislativo, Executivo e Judiciário, implementem ações para que haja efetividade no direito, notadamente sobre os direitos sociais e as políticas públicas apropriadas, nas perspectivas objetiva e subjetiva de suas normas e orientações definidoras do fiel cumprimento desses direitos e garantias.

A proteção e defesa do consumidor é considerada pelos autores estudados como direito coletivo; o princípio da socialidade deve preponderar, pois reflete a prevalência dos valores coletivos sobre os individuais, todavia, sem desconsiderar a pessoalidade do indivíduo. Nessa perspectiva, os contratantes devem observar o requisito de validade, em respeito a ambas as partes, na celebração do contrato. Todos, entretanto, concordam que, se houver danos, a devida reparação é necessária.

A IES deve orientar-se pelas normas vigentes e primar por ações condizentes com as metas traçadas; motivar os estudantes a se comprometerem para que a relação entre todos os atores envolvidos seja harmoniosa. Disponibilizar os recursos, contratar professores com conhecimentos e habilidades é fundamental; publicar planos de ação e forma para desenvolvimento das atividades constitui obrigatoriedade, e de forma antecedente ao semestre programado. De outro lado, familiares e, principalmente, estudantes devem se envolver e se comprometer com o processo da aprendizagem, visto que o conhecimento é o bem imaterial mais importante que se possa conquistar, embora, em sua plenitude, é inalcançável. 
O Direito muda, por não se tratar de simples teoria, e nós também temos de mudar nossas práticas, calcados em projetos robustos e coerentes com nossos ideais. Assim, com este estudo, não se pretendeu esgotar o assunto. Sugerem-se, para outras pesquisas, novas incursões que possam permitir melhor analisar a efetividade dos direitos e garantias dos usuários do ensino. Para as próximas produções merecerão atenção as práticas realizadas em tempos de pandemia e casos reais jurisprudenciais envolvendo a atuação de IES e demais partícipes.

\section{REFERÊNCIAS}

BRASIL. Lei $\mathrm{n}^{\circ} 10.406$, de 10 de janeiro de 2002. Institui o Código Civil. Diário Oficial da União: seção 1, Brasília, DF, ano 139, n. 8, p. 1-74, 11 jan. 2002. PL 634/1975.

BRASIL. Lei no 8.078 , de 11 de setembro de 1990. Dispõe sobre a proteção do consumidor e dá outras providências. DOU de 12.09.1990. Disponível em:

http://www.planalto.gov.br/ccivil_03/leis/18078compilado.htm. Acesso em: 20 set. 2020.

BRASIL. Lei $\mathrm{n}^{\circ}$ 9.394, de 20 de dezembro de 1996. Estabelece as diretrizes e bases da educação nacional. D.O.U., CXXXIV, n. 248, 23.12.96, p. 27833-27841. Disponível em: http://www.planalto.gov.br/ccivil_03/leis/L9394.htm. Acesso em: 2 ago.2020.

BRASIL. [Constituição (1988)]. Constituição da República Federativa do Brasil de 1988. Brasília, DF: Presidência da República, [2020]. Disponível em:

http://www.planalto.gov.br/ccivil_03/constituicao/constituicao.htm Acesso em: 19 ago.2020.

INSTITUTO NACIONAL DE ESTUDOS E PESQUISAS ANÍSIO TEIXEIRA (INEP). Nota Técnica $\quad \mathrm{n}^{\circ} \quad$ 16/2017/CGACG/IES/DAES. Disponível em: http://download.inep.gov.br/educacao_superior/avaliacao_cursos_graduacao/legislacao_norm as/2017/nota_tecnica_sei_inep_0126132.pdf. Acesso em: 12 set. 2020.

INSTITUTO NACIONAL DE ESTUDOS E PESQUISAS ANÍSIO TEIXEIRA (INEP). Instrumento de avaliação e reconhecimento de cursos - reconhecimento e renovação de reconhecimento de cursos presenciais e a distância, outubro de 2017. Disponível em: http://download.inep.gov.br/educacao_superior/avaliacao_cursos_graduacao/instrumentos/20 17/curso_autorizacao.pdf. Acesso em: 09 set. 2020.

INSTITUTO NACIONAL DE ESTUDOS E PESQUISAS ANÍSIO TEIXEIRA (INEP). Avaliação in loco e novos instrumentos de avaliação de instituições de educação superior e cursos de graduação: subsídios para a atuação de Procuradores Institucionais (PI) - 2018. Disponível em:

http://download.inep.gov.br/educacao_superior/avaliacao_institucional/avaliacao_in-loco/ Capacitacao_Procuradores_Educacionais_Institucionais_2018.pdf. Acesso em: 2 jun. 2019. 
DINIZ, Maria Helena. Curso de direito civil brasileiro: teoria das obrigações contratuais e extracontratuais. 33. ed. São Paulo: Saraiva, 2017.

GONÇALVES, Carlos Roberto. Direito civil brasileiro: contratos e atos unilaterais. 15. ed. São Paulo: Saraiva, 2016.

LAKATOS, Eva Maria; MARCONI, Marina de Andrade. 20. ed. Metodologia científica. São Paulo: Editora Atlas, 2017.

MARQUES, Cláudia Lima; BENJAMIN, Antônio Herman V.; MIRAGEM, Bruno. Comentários ao código de defesa do consumidor. São Paulo: Editora Revista dos Tribunais, 2010.

NUNES JÚNIOR, Flávio Martins Alves. Curso de direito constitucional. São Paulo: Thomson Reuters Brasil, 2018.

RAMOS, André Luiz Santa Cruz. Direito empresarial. 7. ed. São Paulo: Editora Método, 2017.

VENOSA, Sílvio Salvo. Direito civil: responsabilidade civil. 18. ed. São Paulo: Atlas, 2018. 